\title{
Polymorphism analysis in genes associated with meat tenderness in Nelore cattle
}

\author{
Camila Urbano Braz ${ }^{\mathrm{a}, *}$, Jeremy Francis Taylor ${ }^{\mathrm{b}}$, Jared Egan Decker ${ }^{\mathrm{b}}$, Tiago Bresolin ${ }^{\mathrm{a}}$, \\ Rafael Espigolan ${ }^{a}$, Diogo Anastácio Garcia a , Daniel Gustavo Mansan Gordo a, \\ Ana Fabrícia Braga Magalhães ${ }^{\mathrm{a}}$, Lucia Galvão de Albuquerque ${ }^{\mathrm{a}}$, Henrique Nunes de Oliveira ${ }^{\mathrm{a}}$ \\ a Animal Science Department, São Paulo State University (UNESP), School of Agricultural and Veterinarian Science, Jaboticabal, SP 144884-900, Brazil \\ ${ }^{\mathrm{b}}$ Division of Animal Sciences, University of Missouri, Columbia, MO 65211, USA
}

A R T I C L E I N F O

\section{Keywords:}

ASAP1

Candidate gene

CAPN1

Haplotype

Polymorphism

WBSF

\begin{abstract}
A B S T R A C T
The aims of this study were to identify haplotyped loci associated with meat tenderness (WBSF) in candidate genes and to search for new polymorphisms in these regions that influence such trait in Nelore cattle. Fifty-two genes that had previously been associated with WBSF or that have biological functions that may influence tenderness were chosen for the haplotype association analysis in 1657 animals. Of the 52 tested candidate genes, two haplotyped loci located in ASAP1 and CAPN1 were significantly associated with WBSF. The effect of the significant haplotype alleles varied from -0.44 to 0.80 and -1.03 to $1.52 \mathrm{~kg}$ in CAPN1 and ASAP1, respectively. Exonic regions near and within these loci were chosen for sequencing to search for new polymorphisms. Four SNPs were identified in ASAP1 and seventeen in CAPN1. All SNPs detected in the sequenced regions in ASAP1 showed no association with WBSF even though two of them (rs714391435 and rs109256712) were in strong linkage disequilibrium (LD) with most SNPs that composed the significant haplotyped locus. Four SNPs located in CAPN1 were found for the first time in this study. One of them (rs1121961662) showed significant association with WBSF and is also in strong LD with all SNPs within the significant haplotyped locus in CAPN1 gene. The SNP rs1121961662 could be used as a molecular marker for this QTL and may be included in lowdensity arrays to improve the selection of meat tenderness in Bos indicus animals.
\end{abstract}

\section{Introduction}

Brazil has been a major global producer and exporter of beef for over a decade (Anualpec, 2016) and the Brazilian herd composition is predominantly Bos indicus, with Nelore being the most prominent beef breed. Bos indicus breeds produce beef of lower tenderness than Bos taurus breeds (O'Connor et al., 1997; Bianchini et al., 2007) and meat tenderness is considered to be the most important trait influencing consumer satisfaction, impacting the profitability of the entire beef industry (Huffman et al., 1996; Boleman et al., 1997; Goodson et al., 2002). However, meat tenderness is a complex trait in which many genetic and non-genetic factors affecting it (Hocquette et al., 2012) and is expressed late in the animal's life when measured post-mortem. As a consequence, the genetic improvement of meat tenderness in beef cattle has been slow (Gutiérrez-Gil et al., 2008; Dunner et al., 2013). Therefore, the search for trait-associated SNP markers has become an important tool to identify quantitative trait loci (QTL), candidate genes and causal mutations that influence meat tenderness (Page et al., 2004; Van den Berg et al., 2013).

Candidate gene-association mapping approach can be effectively used to analyze genes with known function related to complex traits with higher statistical power when compared to GWA studies (Kwon and Goate, 2000; Patnala et al., 2013; Amos et al., 2011). Another strategy to increase the power for the identification of significant genomic regions is through haplotype-based association methods. Haplotypes are multi-allelic, reduce the number of tests and may capture more of the available linkage disequilibrium (LD) with QTL loci (Zhao et al., 2007; Cuyabano et al., 2014). The combination of these two approaches increases the chance of detecting regions that truly influence complex traits and may be explored more deeply to search for new polymorphisms that could be useful in selection programs. Therefore, the aims of this study were to identify haplotyped loci associated with meat tenderness in candidate genes and to search for new polymorphisms in these regions that influence such trait in Nelore

\footnotetext{
* Corresponding author.

E-mail address: camila_urbano@yahoo.com.br (C.U. Braz).
} 
cattle.

\section{Material and methods}

\subsection{Animals}

A total of 1657 Nelore bulls born between 2008 and 2011, raised on pasture and sourced from three different animal breeding programs were used in this study. The animals were finished in feedlots for approximately 90 days and then slaughtered in commercial slaughterhouses at a mean age of $729 \pm 81$ days. The animals belonged to 165 contemporary groups (CG) defined by the combination of farm and year of birth, management group as long-yearlings and month and year of slaughter. There were at least two animals in every CG.

\subsection{Phenotype and genotype data}

Briefly, to obtain the tenderness phenotypes, animals were slaughtered and the carcasses were identified and chilled for 24 to 48 hour post-mortem. Steaks of $2.54 \mathrm{~cm}$ thickness were collected from the longissimus thoracis muscle between the 12th and 13th ribs from the left half of the carcasses. The steaks were vacuum sealed and aged in a cold chamber for $150 \mathrm{~h}$ at $1{ }^{\circ} \mathrm{C}$ and then were frozen at $-20^{\circ} \mathrm{C}$ until they were later cooked in an oven to an internal temperature of $71^{\circ} \mathrm{C}$ as proposed by Wheeler et al. (1995). After cooking, steaks were chilled overnight at 2 to $5^{\circ} \mathrm{C}$ before coring. The Warner-Bratzler shear force (WBSF), a mechanical measurement of tenderness, was measured using a Salter shearing device (G-R Electric, Manhattan, KS). For precision, eight $1.27 \mathrm{~mm}$ meat cylinders were obtained from each sample and the average shear force was used in analysis. The mean of WBSF was $5.21 \pm 1.38 \mathrm{~kg}$ with a minimum value of $1.56 \mathrm{~kg}$ and a maximum of $11.20 \mathrm{~kg}$.

Tissues from the longissimus thoracis muscle were used to extract DNA using a DNeasy Blood \& Tissue Kit (Qiagen GmbH, Hilden, Germany) according to the manufacturer's instructions. Genotyping was performed by high-density bead array technology using the Illumina (San Diego, CA) BovineHD Infinium Assay ${ }^{\circledR}$ with an Illumina HiScan System $^{\circledast}$. The BovineHD BeadChip contains 777,962 SNP markers evenly distributed throughout the genome with a 3.43 kilobase $(\mathrm{kb})$ average separation between the markers. The Illumina Genome Studio software was used to analyze the HiScan images to call genotypes. Forty-one samples for which the genotype call rate was $<90 \%$ were removed. The SNP markers with a call rate of $<95 \%$ or with a minor allele frequency $<5 \%$, Hardy Weinberg equilibrium test statistic probability $<10^{-5}$ or that were unmapped to autosomes or sex-linked were also excluded. After quality control a total of 1616 samples remained for analysis.

\subsection{Candidate gene analysis}

Fifty-two genes that had previously been associated with meat quality or that have biological functions that may influence tenderness were chosen for analysis and are described in Supplementary Table 1. The genomic coordinates for each gene based on the Bos taurus UMD3.1 reference assembly were expanded by $1500 \mathrm{bp}$ upstream and downstream due to their potential for harboring regulatory elements and missing exons within the assembly (Whitacre et al., 2015). A total of 985 SNPs on the BovineHD assay were identified within these regions.

The software fastPHASE (Scheet and Stephens, 2006) was used for haplotype reconstruction and missing genotype estimation. The linkage disequilibrium (LD) calculation between SNPs and the haplotype block definition were performed using HaploView software (Barrett et al., 2005) based on estimates of D' (Gabriel et al., 2002).

Statistical analyses incorporating haplotype information were performed using the MIXED procedure of the SAS 9.3 (SAS Institute, 2011), for each haplotyped locus, as follows:

$$
y_{i j k}=c_{i}+s_{i}+\sum_{l=1}^{n-1} b_{l} x_{l i}+e_{i}
$$

where, $y$ is the WBSF phenotypes for animal $i$; $c$ is the fixed effect of CG for animal $i$; $s$ is the random effect of sire for animal $i ; b$ is the regression coefficient of the number of copies of the allele $l ; x$ is the number of copies of the allele $l$ for animal $i$; $e$ is the random error for animal $i$; and $n$ is the haplotype allele number. The Bonferroni test was applied at an experiment-wise $10 \%(\mathrm{P} \leq 0.00028)$ error rate to adjust for multiple testing.

\subsection{Sequencing}

Exons of each candidate gene located within, or adjacent to, the haplotyped loci that were significantly associated with WBSF were chosen for sequencing in 25 animals with the lowest degree of relatedness among the 1616 animals to identify polymorphic regions, since they are more likely to be genetically different from each other. After, the polymorphic regions were sequenced in 298 animals that belonging to the CGs from the initial 25 sequenced animals.

Primers were designed to amplify these regions (based on Gene ID: 281661 and 327705) using Primer3 software and their specificity was verified using OligoAnalyzer 3.1. The polymerase chain reaction amplification mixture contained $1.0 \mu \mathrm{L}$ DNA $(60 \mathrm{ng} / \mu \mathrm{l}), 1.5 \mu \mathrm{L}$ of each primer (15 pM), 7.5 $\mu \mathrm{L}$ GoTaq Colorless Master Mix and $3.5 \mu \mathrm{L}$ nuclease-free water in a final volume of $15 \mu \mathrm{L}$. A Master Cycler Gradient 5331 thermal cycler was used to perform the amplification using the conditions: denaturation at $95^{\circ} \mathrm{C}$ for $5 \mathrm{~min}$, followed by 30 cycles of denaturation at $95^{\circ} \mathrm{C}$ for $1 \mathrm{~min}$, annealing temperature dependent on each primer (Supplementary Table 2) for $1 \mathrm{~min}$ and extension at $72^{\circ} \mathrm{C}$ for $1 \mathrm{~min}$, with a final extension step at $72{ }^{\circ} \mathrm{C}$ for $5 \mathrm{~min}$. Twenty-five unrelated animals were individually sequenced to identify variants in the amplicons produced by each primer pair. Sequencing was performed by the dideoxynucleotide chain termination reaction on an ABI 3730 XL sequencer using the ABI PRISM BigDye Terminator Cycle Sequencing Ready Reaction kit (Applied Biosystems, Foster City, CA). Polymorphisms within each amplicon were identified using the CodonCode Aligner program.

\subsection{Polymorphism association analyses}

In order to increase the number of individuals analyzed, genotypes called from the sequence data produced for the SNPs discovered in the sequenced genes were merged with the SNPs from the BovineHD assay and genotypes were imputed for all 1616 animals using BEAGLE v3.3.2 (Browning and Browning, 2007). HaploView software was used to perform the tests of Hardy-Weinberg equilibrium (HWE) for each SNP and to calculate the LD between SNPs. The same statistical analysis described for candidate genes analysis (above) was performed to the SNPs discovered in the sequenced genes. The SNP rs714391435 were not included in the association analysis due to its very low MAF (0.02). The Bonferroni correction was applied at the $5 \%$ level to adjust for multiple testing ( $\mathrm{P} \leq 0.0025)$.

\section{Results and discussion}

Two haplotyped loci were significantly associated with meat tenderness using the Bonferroni correction $(\mathrm{P} \leq 0.00028)$ and were located in the ASAP1 and CAPN1 genes (Table 1). The haplotyped locus in ASAP1 was composed of 21 SNPs spanned 36,884 bp in intron 3 and the haplotyped locus in CAPN1 spanned 3,128 bp with 3 SNPs between intron 13 and 19. The haplotype alleles, their frequencies and average effect are shown in Table 2. In ASAP1, the most favorable haplotype allele (GGGTACCAGCGGGCCAAAGTG) decreased $1.03 \mathrm{~kg}$ in WBSF and was observed at $7.6 \%$ frequency in this population. In CAPN1, the haplotype allele ATG showed the most favorable effect $(-0.44 \mathrm{~kg})$ on 
Table 1

Description of the haplotyped loci significantly associated with meat tenderness after Bonferroni correction.

\begin{tabular}{|c|c|c|c|c|c|}
\hline Gene & RefSNP & Chr & Pos & Region & Length \\
\hline ASAP1 & $\begin{array}{l}\text { rs110237617 - rs110329676 - rs110543908 - rs109736419 - rs109890073 - rs110270007 - rs136043279 - } \\
\text { rs109331471 - rs110421714 - rs110868560 - rs109150109 - rs110631693 - rs110205824 - rs109516020 - } \\
\text { rs109758436 - rs109254655 - rs110869257 - rs109958399 - rs134375889 - rs109522060 - rs41627745 }\end{array}$ & 14 & $11,494,742-11,531,625$ & I 3 & 36,884 \\
\hline CAPN1 & rs17871058 - rs17872050 - rs17870847 & 29 & $44,085,769-44,088,897$ & I 13-19 & 3,128 \\
\hline
\end{tabular}

RefSNP, reference SNP ID number; Chr, chromosome; Pos, haplotype initial and final position in base pairs; I, intron; Length, haplotype length in base pairs.

Table 2

Frequency, average effect and respective standard error (SE) of the haplotyped loci alleles significantly associated with meat tenderness.

\begin{tabular}{llll}
\hline Genes & Alleles & Frequency & Average effect (SE) \\
\hline \multirow{2}{*}{ ASAP1 } & TATCCTTCATAAATTGGGGCT & 0.447 & $0.07(0.30)$ \\
& GGTTCTTCATAAATTGGGGTG & 0.339 & $-0.25(0.32)$ \\
& GGGTACCAGCGGGCCAAAGTG & 0.076 & $-1.03(0.51)$ \\
& GGGTACCAGCGGGCCAAAATG & 0.049 & $-0.40(0.60)$ \\
& GGTCCTTCATAAACTAGGGCG & 0.044 & $-0.08(0.65)$ \\
& GGTTCTTCATAAACTAGGGTG & 0.033 & $-0.13(0.73)$ \\
& GGTTACCAGCGGGCCAAAGTG & 0.012 & $1.52(0.64)$ \\
& GTG 1 & 0.591 & $-0.20(0.14)$ \\
& GTA & 0.185 & $-0.17(0.16)$ \\
& ATG & 0.121 & $-0.44(0.23)$ \\
& GCA & 0.103 & $0.80(0.29)$ \\
\hline
\end{tabular}

WBSF and was present in this population at $12.1 \%$ frequency.

The ASAP1 gene (ArfGAP with SH3 domain, Ankyrin repeat and PH domain 1), also known as DDEF1 (Gene ID: 327705), is located on chromosome 14 and encodes a signal transduction protein that enhances the potential of fibroblasts to differentiate into adipocytes (King et al., 1999). Cruz et al. (2012) reported that meat tenderness scores were significantly associated with adipocyte cell numbers and also proposed that increasing the numbers of adipocytes would lead to improved tenderness. Adipocytes are the cells that comprise adipose tissue found in subcutaneous, visceral, intermuscular and intramuscular (marbling) adipose depots (Hausman et al., 2014). Subcutaneous fat insulates the carcass and slows post-mortem chilling, which may improve tenderness by reducing the extent of cold-shortening and marbling improves meat tenderness by reducing tissue density and decreasing the strength of connective tissues (Fiems et al., 2000; Hausman et al., 2009). Tizioto et al. (2012), Tizioto et al. (2013) and RamayoCaldas et al. (2016) showed association of SNPs in ASAP1 with meat tenderness in Nelore and French beef breeds.

The CAPN1 gene (Gene ID: 281661) is located on chromosome 29 and encodes $\mu$-calpain, the micromolar calcium activated neutral protein, which degrades myofibrillar proteins post-mortem. The calcium dependent proteolytic system has long been considered to be among the most important factors responsible for variation in post-mortem tenderization (Croall and DeMartino, 1991; Koohmaraie, 1994; Koohmaraie, 1996). A number of studies have shown significant associations between CAPN1 and shear force, suggesting that variants in this gene may be responsible for variation in meat tenderness (Page et al., 2002; Casas et al., 2005; Casas et al., 2006; White et al., 2005; Curi et al., 2009).

For ASAP1, we sequenced only exon 4 due to its proximity to the significant haplotyped region and nine exons were located near or in the significant haplotyped region in CAPN1 (Supplementary Table 2). The sequencing identified 21 SNPs, with 17 SNPs in CAPN1 spanning part of intron 12 through part of intron 21 and 4 SNPs in ASAP1, including exon 4 and a part of intron 4 (Table 3). The SNP rs109552294, located in exon 4 of $A S A P 1$, is a synonymous substitution and the remaining SNPs are in intron 4. Among the detected SNPs in CAPN1, the SNP $r s 17871050$ is a synonymous substitution while the SNP rs17871051 produces a valine to isoleucine substitution (Val530Ile) in exon 14 of CAPN1 and the remaining SNPs are located in introns. The
Table 3

Description of the SNPs found in the candidate tenderness genes in Nelore cattle.

\begin{tabular}{llllll}
\hline Gene & Chr & RefSNP & Position & Region & Consequence \\
\hline ASAP1 & \multirow{2}{*}{14} & $r s 109552294$ & $11,558,261$ & Exon 4 & Synonymous \\
& & $r s 109256712$ & $11,558,286$ & Intron 4 & \\
& & $r s 211332127$ & $11,558,293$ & Intron 4 & \\
CAPN1 & 29 & $r s 714391435$ & $11,558,324$ & Intron 4 & \\
& & $r s 481432081$ & $44,085,260$ & Intron 12 & Synonymous \\
& & $r s 17871050$ & $44,085,638$ & Exon 14 & \\
& & $r 17871051$ & $44,085,642$ & Exon 14 & Non-synonymous \\
& $r s 1121961662$ & $44,086,321$ & Intron 15 & \\
& $r s 721496944$ & $44,086,442$ & Intron 16 & \\
& & $r s 464736006$ & $44,086,508$ & Intron 16 & \\
& & $r s 17872152$ & $44,088,005$ & Intron 18 & \\
& $r s 17872153$ & $44,088,027$ & Intron 18 & \\
& $r s 110896665$ & $44,088,036$ & Intron 18 & \\
& $r s 1131232536$ & $44,088,078$ & Intron 18 & \\
& $r s 447978510$ & $44,088,087$ & Intron 18 & \\
& $r s 1118716870$ & $44,088,126$ & Intron 18 & \\
& $r s 1122971334$ & $44,088,158$ & Intron 18 & \\
& $r s 715244311$ & $44,088,332$ & Intron 19 & \\
& $r s 110022482$ & $44,089,241$ & Intron 20 & \\
& $r s 110480144$ & $44,089,263$ & Intron 20 & \\
& $r s 719993085$ & $44,089,483$ & Intron 21 & \\
& & & &
\end{tabular}

RefSNP, reference SNP ID number; Position, UMD3.1 coordinate of the SNP on the chromosome (base pair).

sequences containing the polymorphisms were submitted to NCBI under accession numbers KT023263.1 and KT023264.1. The SNPs rs1121961662, rs1131232536, rs1118716870 and rs1122971334, located in CAPN1, were identified for the first time in this study and were deposited into NCBI's dbSNP database.

In the intron 18 of CAPN1, where the SNPs rs447978510, rs1118716870 and rs1122971334 were located, there is also the microRNA 2407 (Gene ID: 100313430) located from 44,088,087 to $44,088,159$ bp (73 nucleotides). MicroRNAs (miRNAs) act as posttranscriptional silencers leading to decreased gene expression and may affect their host gene (Bartel, 2004; Pillai et al., 2007). This miRNA may modulate CAPN1 expression or may regulate genes that cooperate with CAPN1 in its specific biological processes (Lutter et al., 2010; Bosia et al., 2012).

The LD between the SNPs that composed the significant haplotyped loci and the SNPs detected in the sequenced regions are shown as a heat map of the estimates of D' in Fig. 1. In ASAP1, the four SNPs detected in the sequenced regions ( $r s 109552294$, rs109256712, rs211332127 and rs714391435) were in strong LD between them. However, only the SNPs $r s 714391435$ and $r s 109256712$ were in strong LD with most SNPs that composed the significant haplotyped locus. In CAPN1, all SNPs detected in the sequenced regions were in strong LD with the three SNPs within the significant haplotyped locus ( $r s 17871058$, rs17872050 and rs17870847), but the SNPs rs17871058 and rs719993085, rs17870847 and rs481732081 that showed low LD between them. The four SNPs identified for the first time in a bovine population (rs1121961662, rs1131232536, rs1118716870 and rs1122971334) also were in strong LD with each other. According to Pritchard and Przeworski (2001) SNPs in strong LD tend to be inherited together more often than would be expected by chance. 

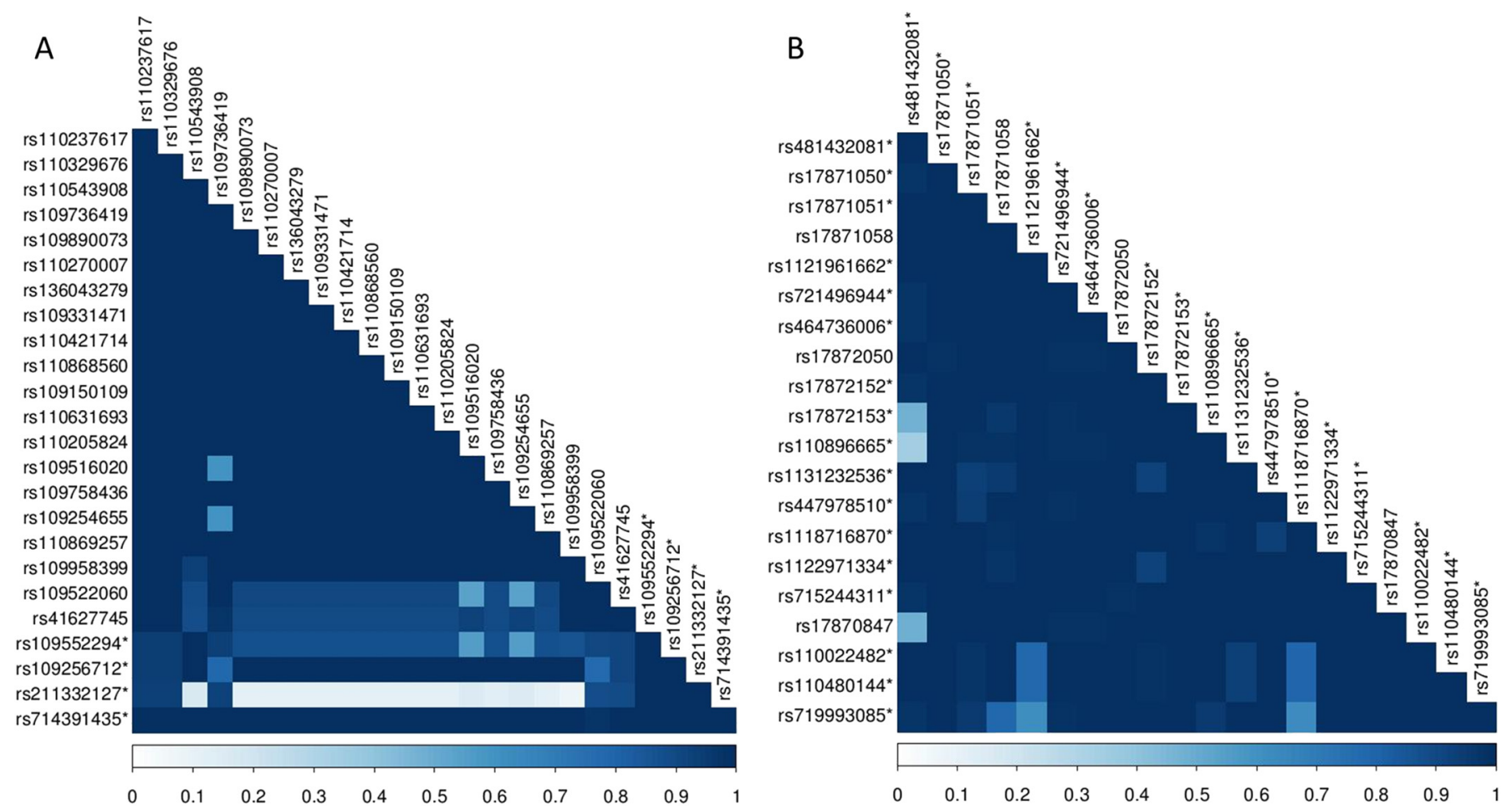

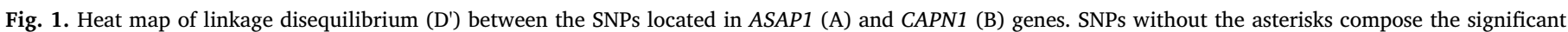
haplotyped loci and SNPs with asterisks were discovered in the sequenced regions. Darker shading indicates regions of higher linkage disequilibrium.

Table 4

Allele frequency, effect and P-values for SNPs found in the tenderness candidate genes.

\begin{tabular}{|c|c|c|c|c|c|c|c|c|c|}
\hline \multirow[t]{2}{*}{ Gene } & \multirow[t]{2}{*}{ RefSNP } & \multicolumn{2}{|c|}{ Allele frequency } & \multicolumn{3}{|c|}{ Genotype Frequency } & \multirow[t]{2}{*}{ HWEpval } & \multirow[t]{2}{*}{ Effect } & \multirow[t]{2}{*}{$\mathrm{P}$-value } \\
\hline & & $\mathbf{A}$ & G & AA & AG & GG & & & \\
\hline ASAP1 & rs211332127 & 0.36 & 0.64 & 0.1219 & 0.4696 & 0.4085 & 0.3815 & 0.017 & 0.2911 \\
\hline CAPN1 & $r s 481432081$ & 0.70 & 0.30 & 0.4937 & 0.4230 & 0.0833 & 0.5238 & -0.007 & 0.5872 \\
\hline CAPN1 & rs17871051 & 0.04 & 0.96 & 0.0006 & 0.0833 & 0.9161 & 0.3919 & -0.147 & 0.4882 \\
\hline CAPN1 & rs17872152 & 0.04 & 0.96 & 0.0006 & 0.0797 & 0.9197 & 0.4760 & -0.129 & 0.5587 \\
\hline CAPN1 & $r s 17872153$ & 0.29 & 0.71 & 0.0760 & 0.4291 & 0.4949 & 0.1112 & -0.016 & 0.5321 \\
\hline CAPN1 & rs1131232536 & 0.11 & 0.89 & 0.0079 & 0.1955 & 0.7966 & 0.1914 & 0.117 & 0.2344 \\
\hline CAPN1 & rs110022482 & 0.96 & 0.04 & 0.9155 & 0.0827 & 0.0018 & 1.0000 & 0.139 & 0.4472 \\
\hline \multirow[t]{2}{*}{ CAPN1 } & $r s 110480144$ & 0.96 & 0.04 & 0.9155 & 0.0827 & 0.0018 & 1.0000 & -0.139 & 0.4472 \\
\hline & & $\mathrm{T}$ & $\mathrm{C}$ & TT & TC & $\mathrm{CC}$ & & & \\
\hline$A S A P 1$ & rs109552294 & 0.54 & 0.46 & 0.2842 & 0.5142 & 0.2016 & 0.1672 & -0.017 & 0.3283 \\
\hline ASAP1 & $r s 714391435$ & 0.02 & 0.98 & 0.000 & 0.0453 & 0.9547 & 0.8491 & - & - \\
\hline CAPN1 & $r s 17871050$ & 0.19 & 0.81 & 0.0266 & 0.3204 & 0.6530 & 0.0231 & -0.080 & 0.5088 \\
\hline CAPN1 & $r s 464736006$ & 0.81 & 0.18 & 0.6512 & 0.3223 & 0.0265 & 0.0231 & 0.073 & 0.5668 \\
\hline CAPN1 & $r s 447978510$ & 0.86 & 0.14 & 0.7435 & 0.2348 & 0.0217 & 0.4677 & 0.045 & 0.6147 \\
\hline CAPN1 & rs1118716870 & 0.07 & 0.93 & 0.0036 & 0.1268 & 0.8696 & 0.7557 & -0.168 & $0.0036^{*}$ \\
\hline CAPN1 & rs1122971334 & 0.11 & 0.89 & 0.0079 & 0.1949 & 0.7972 & 0.2004 & 0.113 & 0.2567 \\
\hline CAPN1 & $r s 715244311$ & 0.19 & 0.81 & 0.0266 & 0.3198 & 0.6536 & 0.0311 & -0.082 & 0.4983 \\
\hline \multirow[t]{2}{*}{ CAPN1 } & rs719993085 & 0.14 & 0.86 & 0.0253 & 0.2342 & 0.7405 & 0.1149 & -0.069 & 0.4598 \\
\hline & & $\mathrm{T}$ & G & TT & TG & GG & & & \\
\hline \multirow[t]{2}{*}{ CAPN1 } & rs110896665 & 0.43 & 0.57 & 0.1762 & 0.5063 & 0.3175 & 0.1961 & -0.041 & 0.8918 \\
\hline & & G & $\mathrm{C}$ & GG & GC & $\mathrm{CC}$ & & & \\
\hline$A S A P 1$ & $r s 109256712$ & 0.49 & 0.51 & 0.2299 & 0.5184 & 0.2517 & 0.1450 & 0.004 & 0.7274 \\
\hline \multirow[t]{2}{*}{ CAPN1 } & rs1121961662 & 0.93 & 0.07 & 0.8714 & 0.1255 & 0.0031 & 0.5310 & 0.187 & $0.0023^{* * *}$ \\
\hline & & $\mathbf{A}$ & $\mathrm{C}$ & AA & AC & CC & & & \\
\hline CAPN1 & $r s 721496944$ & 0.19 & 0.81 & 0.0278 & 0.3205 & 0.6517 & 0.0498 & -0.077 & 0.5316 \\
\hline
\end{tabular}

RefSNP, reference SNP ID number; HWEpval, P-values for the tests of Hardy-Weinberg equilibrium; effect, allelic substitution effect.

** P-value after Bonferroni correction at $5 \%(\mathrm{P} \leq 0.0025)$

* P-value after Bonferroni correction at 10\% (P $\leq 0.005)$.

The allele and genotype frequencies, P-values for HWE, allelic substitution effect and the result of the association analysis of the SNPs detected in the sequenced regions are presented in Table 4. All SNPs detected in the sequenced regions were in HWE ( $P \geq 0.001)$. Few SNPs in ASAP1 have been shown to affect WBSF in Nelore (Tizioto et al., 2012 and Tizioto et al., 2013) and French beef breeds (Ramayo-Caldas et al., 2016). The associations of the four SNPs found in ASAP1 in this study with WBSF have not previously been investigated in beef cattle; 
however, they showed low effect and no evidence of association with WBSF in the population studied.

Several studies have reported SNPs located in exons and introns of CAPN1 affecting WBSF in Bos taurus, Bos indicus and crossbred populations (Casas et al., 2006; Curi et al., 2009; Page et al., 2002; McClure et al., 2012). However, studies investigating the associations of the SNPs found in CAPN1 in this study were not found in the literature, except for the SNP rs17871051, which has previously been reported to be associated with WBSF in beef cattle (Page et al., 2002; Page et al., 2004; Lee et al., 2014; McClure et al., 2012). Only the SNP rs1121961662, located in intron 15 of CAPN1, showed significant association with WBSF, after Bonferroni correction at $5 \%$ ( $\mathrm{P} \leq 0.0025)$, and the greatest allelic substitution effect $(0.185 \mathrm{~kg})$. SNPs located in intron may be in strong LD with the causal mutation or may be regulatory elements influencing the expression of the genes that host them (Cooper, 2010). This SNP (rs1121961662) is in strong LD with the SNP rs17871051 which showed no association with WBSF in the present study and this lack of association could be due to the low frequency of the A allele (0.04). Pinto et al. (2010) also reported low frequency of the A allele and no association with WBSF of the SNP rs17871051 in another Nelore cattle population. Casas et al. (2005) reported that the G allele seemed to be fixed in Brahman (Bos indicus). Therefore, the SNP rs1121961662 could be used as a molecular marker for this QTL and included in low-density arrays to improve the selection of meat tenderness in Bos indicus breeds.

\section{Conclusions}

Haplotypes capturing the linkage disequilibrium between markers allowed the identification of two significant regions in ASAP1 and CAPN1 influencing meat tenderness in Nelore cattle. One polymorphism ( $r$ 1121961662), detected for the first time in a bovine population, was associated with meat tenderness and was in strong linkage disequilibrium with the significant haplotyped locus in CAPN1 gene. Future investigation to better understand how these genes are influencing meat tenderness and to validate the SNP rs1121961662 could be helpful to improve such trait in Nelore cattle.

\section{Funding}

This work was supported by the São Paulo Research Foundation (FAPESP) and National Council for Scientific and Technological Development (CNPq) grants: \#2009/16118-5 and \#480369/2009-7, respectively. São Paulo Research Foundation (FAPESP) also funds the scholarships \#2013/00035-9 and \#2014/23013-3 to Camila U. Braz.

\section{Authors' contributions}

CUB conceived the study, analyzed and interpreted the results and, wrote the manuscript. RE, DAG, DGMG and AFBM helped conceive the study. JFT, JED and LGA assisted with preparation of the manuscript and aided with interpretation of results; TB and HNO assisted with analyses, preparation of the manuscript and interpretation of results. All authors read and approved the final manuscript.

\section{Conflicts of interest}

The authors declare no conflicts of interest.

\section{Ethical clearence}

All animal procedures were approved by the São Paulo State University (Unesp), School of Agricultural and Veterinary Science Ethical Committee (Approval No. 18.340/16).

\section{Acknowledgements}

The authors would like to acknowledge the DeltaGen, PAINT and Cia de Melhoramento breeding programs for providing data. We also would like to acknowledge the members of the Animal Breeding and Genetics Postgraduate Program (PPGMA) of the São Paulo State University (FCAV/Unesp) for their assistance with collecting data.

\section{Appendix A. Supplementary data}

Supplementary data to this article can be found online at https:// doi.org/10.1016/j.mgene.2018.08.002.

\section{References}

Amos, W., Driscoll, E., Hoffman, J.I., 2011. Candidate genes versus genome-wide associations: which are better for detecting genetic susceptibility to infectious disease? Proc. R. Soc. B 278, 1183-1188.

Anualpec, 2016. Anuário da Pecuária Brasileira. AgraFNP, São Paulo, pp. 407.

Barrett, J.C., Fry, B., Maller, J., Daly, M.J., 2005. Haploview: analysis and visualization of LD and haplotype maps. Bioinformatics 21, 263-265.

Bartel, D.P., 2004. MicroRNAs: genomics, biogenesis, mechanism, and function. Cell 116, 281-297.

Bianchini, W., Silveira, A.C., Jorge, A.M., Arrigoni, M.D.B., Martins, C.L., Rodrigues, É., Hadlich, J.C., Andrighetto, C., 2007. Efeito do grupo genético sobre as características de carcaça e maciez da carne fresca e maturada de bovinos superprecoces. Rev. Bras. Zootec. 36, 2109-2117.

Boleman, S.J., Boleman, S.L., Miller, R.K., Taylor, J.F., Cross, H.R., Wheeler, T.L., Koohmaraie, M., Shackelford, S.D., Miller, M.F., West, R.L., Johnson, D.D., Savell, J.W., 1997. Consumer evaluation of beef of known categories of tenderness. J. Anim. Sci. 75, 1521-1524.

Bosia, C., Osella, M., Baroud, M., Cora, D., Caselle, M., 2012. Gene autoregulation via intronic microRNAs and its functions. BMC Syst. Biol. 6, 131.

Browning, S.R., Browning, B.L., 2007. Rapid and accurate haplotype phasing and missing data inference for whole-genome association studies by use of localized haplotype clustering. Am. J. Hum. Genet. 81, 1084-1097.

Casas, E., White, S.N., Riley, D.G., Smith, T.P., Brenneman, R.A., Olson, T.A., Johnson, D.D., Coleman, S.W., Bennett, G.L., Chase Jr., C.C., 2005. Assessment of single nucleotide polymorphisms in genes residing on chromosomes 14 and 29 for association with carcass composition traits in Bos indicus cattle. J. Anim. Sci. 83, 13-19.

Casas, E., White, S.N., Wheeler, T.L., Shackelford, S.D., Koohmaraie, M., Riley, D.G., Chase Jr., C.C., Johnson, D.D., Smith, T.P., 2006. Effects of calpastatin and microcalpain markers in beef cattle on tenderness traits. J. Anim. Sci. 84, 520-525.

Cooper, D.N., 2010. Functional intronic polymorphisms: buried treasure awaiting discovery within our genes. Hum. Genomics 4, 284-288.

Croall, D.E., DeMartino, G.N., 1991. Calcium-activated neutral protease (calpain) system: structure, function, and regulation. Physiol. Rev. 71, 813-847.

Cruz, G.D., Strathe, A.B., Rossow, H.A., Fadel, J.G., 2012. Characterizing bovine adipocyte distribution and its relationship with carcass and meat characteristics using a finite mixture model. J. Anim. Sci. 90, 2995-3002.

Curi, R.A., Chardulo, L.A.L., Mason, M.C., Arrigoni, M.D.B., Silveira, A.C., De Oliveira, H.N., 2009. Effect of single nucleotide polymorphisms of CAPN1 and CAST genes on meat traits in Nellore beef cattle (Bos indicus) and in their crosses with Bos taurus. Anim. Genet. 40, 456-462.

Cuyabano, B.C., Su, G., Lund, M.S., 2014. Genomic prediction of genetic merit using LD based haplotypes in the Nordic Holstein population. BMC Genomics 15, 1171.

Dunner, S., Sevane, N., García, D., Cortés, O., Valentini, A., Williams, J.L., Mangind, B., Cañóna, J., Levéziele, H., GeMQual Consortium, 2013. Association of genes involved in carcass and meat quality traits in 15 European bovine breeds. Livest. Sci. 154, 34-44.

Fiems, L.O., Campeneere, S.D., De Smet, S., Van de Voorde, G., Vanacker, J.M., Boucqué, C.V., 2000. Relationship between fat depots in carcasses of beef bulls and effect on meat colour and tenderness. Meat Sci. 56, 41-47.

Gabriel, S.B., Schaffner, S.F., Nguyen, H., Moore, J.M., Roy, J., Blumenstiel, B., Higgins, J., DeFelice, M., Lochner, A., Faggart, M., Liu-Cordero, S.N., Rotimi, C., Adeyemo, A., Cooper, R., Ward, R., Lander, E.S., Daly, M.J., Altshuler, D., 2002. The structure of haplotype blocks in the human genome. Science 296, 2225-2229.

Goodson, K.J., Morgan, W.W., Reagan, J.O., Gwartney, B.L., Courington, S.M., Wise, J.W., Savell, J.W., 2002. Beef customer satisfaction: factors affecting consumer evaluations of clod steaks. J. Anim. Sci. 80, 401-408.

Gutiérrez-Gil, B., Wiener, P., Nute, G.R., Burton, D., Gill, J.L., Wood, J.D., Williams, J.L., 2008. Detection of quantitative trait loci for meat quality traits in cattle. Anim. Genet. $39,51-61$.

Hausman, G.J., Dodson, M.V., Ajuwon, K., Azain, M., Barnes, K.M., Guan, L.L., Jiang, Z., Poulos, S.P., Sainz, R.D., Smith, S., Spurlock, M., Novakofski, J., Fernyhough, M.E., Bergen, W.G., 2009. Board-invited review: the biology and regulation of preadipocytes and adipocytes in meat animals. J. Anim. Sci. 87, 1218-1246.

Hausman, G.J., Basu, U., Wei, S., Hausman, D.B., Dodson, M.V., 2014. Preadipocyte and adipose tissue differentiation in meat animals: influence of species and anatomical location. Annu. Rev. Anim. Biosci. 2, 323-351.

Hocquette, J.F., Botreau, R., Picard, B., Jacquet, A., Pethick, D.W., Scollan, N.D., 2012. 
Opportunities for predicting and manipulating beef quality. Meat Sci. 92, 197-209. Huffman, K.L., Miller, M.F., Hoover, L.C., Wu, C.K., Brittin, H.C. Ramsey, C.B., 1996. Effect of beef tenderness on consumer satisfaction with steaks consumed in the home and restaurant. J. Anim. Sci. 74, 91-97.

King, F.J., Hu, E., Harris, D.F., Sarraf, P., Spiegelman, B.M., Roberts, T.M., 1999. DEF-1, a novel Src SH3 binding protein that promotes adipogenesis in fibroblastic cell lines. Mol. Cell. Biol. 19, 2330-2337.

Koohmaraie, M., 1994. Muscle proteinases and meat aging. Meat Sci. 36, 93-104.

Koohmaraie, M., 1996. Biochemical factors regulating the toughening and tenderization processes of meat. Meat Sci. 43, 193-201.

Kwon, J.M., Goate, A.M., 2000. The candidate gene approach. Alcohol Res. Health 24, 164-168.

Lee, S.H., Kim, S.C., Chai, H.H., Cho, S.H., Kim, H.C., Lim, D., Choi, B.H., Dang, C.G. Sharma, A., Gondro, C., Yang, B.S., Hong, S.K., 2014. Mutations in calpastatin and $\mu-$ calpain are associated with meat tenderness, flavor and juiciness in Hanwoo (Korean cattle): molecular modeling of the effects of substitutions in the calpastatin/ $\mu$-calpain complex. Meat Sci. 96, 1501-1508.

Lutter, D., Marr, C., Krumsiek, J., Lang, E., Theis, F., 2010. Intronic microRNAs support their host genes by mediating synergistic and antagonistic regulatory effects. BMC Genomics 11, 224.

McClure, M.C., Ramey, H.R., Rolf, M.M., McKay, S.D., Decker, J.E., Chapple, R.H., Kim, J.W., Taxis, T.M., Weaber, R.L., Schnabel, R.D., Taylor, J.F., 2012. Genome-wide association analysis for quantitative trait loci influencing Warner-Bratzler shear force in five taurine cattle breeds. Anim. Genet. 43, 662-673.

O'Connor, S.F., Tatum, J.D., Wulf, D.M., Green, R.D., Smith, G.C., 1997. Genetic effects on beef tenderness in Bos indicus composite and Bos taurus cattle. J. Anim. Sci. 75, 1822-1830.

Page, B.T., Casas, E., Heaton, M.P., Cullen, N.G., Hyndman, D.L., Morris, C.A., Crawford, A.M., Wheeler, T.L., Koohmaraie, M., Keele, J.W., Smith, T.P., 2002. Evaluation of single nucleotide polymorphisms in CAPN1 for association with meat tenderness in cattle. J. Anim. Sci. 80, 3077-3085.

Page, B.T., Casas, E., Quaas, R.L., Thallman, R.M., Wheeler, T.L., Shackelford, S.D., Koohmaraie, M., White, S.N., Bennett, G.L., Keele, J.W., Dikeman, M.E., Smith, T.P., 2004. Association of markers in the bovine CAPN1 gene with meat tenderness in large crossbred populations that sample influential industry sires. J. Anim. Sci. 82, 3474-3481.

Patnala, R., Clements, J., Batra, J., 2013. Candidate gene association studies: a comprehensive guide to useful in silico tools. BMC Genet. 14, 39.

Pillai, R.S., Bhattacharyya, S.N., Filipowicz, W., 2007. Repression of protein synthesis by
miRNAs: how many mechanisms? Trends Cell Biol. 17, 118-126.

Pinto, L.F., Ferraz, J.B., Meirelles, F.V., Eler, J.P., Rezende, F.M., Carvalho, M.E., Almeida, H.B., Silva, R.C., 2010. Association of SNPs on CAPN1 and CAST genes with tenderness in Nellore cattle. Genet. Mol. Res. 9, 1431-1442.

Pritchard, J.K., Przeworski, M., 2001. Linkage disequilibrium in humans: models and data. Am. J. Hum. Genet. 69, 1-14.

Ramayo-Caldas, Y., Renand, G., Ballester, M., Saintilan, R., Rocha, D., 2016. Multi-breed and multi-trait co-association analysis of meat tenderness and other meat quality traits in three French beef cattle breeds. Genet. Sel. Evol. 48, 37.

SAS Institute Inc, 2011. SAS/STAT Software. SAS Institute Inc, Cary NC (Version 9.3).

Scheet, P., Stephens, M., 2006. A fast and flexible statistical model for large-scale population genotype data: applications to inferring missing genotypes and haplotypic phase. Am. J. Hum. Genet. 78, 629-644.

Tizioto, P.C., Decker, J.E., Taylor, J.F., Schnabel, R.D., Mudadu, M.A., Silva, F.L., Mourão, G.B., Coutinho, L.L., Tholon, P., Sonstegard, T.S., Rosa, A.N., Alencar, M.M., Tullio, R.R., Medeiros, S.R., Nassu, R.T., Feijó, G.L., Silva, L.O., Torres, R.A., Siqueira, F., Higa, R.H., Regitano, L.C., 2012. A SNP in ASAP1 gene is associated with meat quality and production traits in Nelore breed. Meat Sci. 92, 855-857.

Tizioto, P.C., Decker, J.E., Taylor, J.F., Schnabel, R.D., Mudadu, M.A., Silva, F.L., Mourão, G.B., Coutinho, L.L., Tholon, P., Sonstegard, T.S., Rosa, A.N., Alencar, M.M., Tullio, R.R., Medeiros, S.R., Nassu, R.T., Feijó, G.L., Silva, L.O., Torres, R.A., Siqueira, F., Higa, R.H., Regitano, L.C., 2013. Genome scan for meat quality traits in Nelore beef cattle. Physiol. Genomics 45, 1012-1020.

Van den Berg, I., Fritz, S., Boichard, D., 2013. QTL fine mapping with Bayes C( $\pi$ ): a simulation study. Genet. Sel. Evol. 45, 19.

Wheeler, T.L., Koohmaraie, M., Shackelford, S.D., 1995. Standardized Warner-Bratzler Shear Force Procedures for Meat Tenderness Measurement. Clay Center: Roman L. Hruska U. S. MARC. USDA (7 pp.).

Whitacre, L.K., Tizioto, P.C., Kim, J.W., Sonstegard, T.S., Schroeder, S.G., Alexander, L.J. Medrano, J.F., Schnabel, R.D., Taylor, J.F., Decker, J.E., 2015. What's in your nextgeneration sequence data? An exploration of unmapped DNA and RNA sequence reads from the bovine reference individual. BMC Genomics 16, 1114.

White, S.N., Casas, E., Wheeler, T.L., Shackelford, S.D., Koohmaraie, M., Riley, D.G., Chase Jr., C.C., Johnson, D.D., Keele, J.W., Smith, T.P., 2005. A new single nucleotide polymorphism in CAPN1 extends the current tenderness marker test to include cattle of Bos indicus, Bos taurus, and crossbred descent. J. Anim. Sci. 83, 2001-2008.

Zhao, K.Y., Aranzana, M.J., Kim, S., Lister, C., Shindo, C., Tang, C., Toomajian, C., Zheng, H., Dean, C., Marjoram, P., Nordborg, M., 2007. An arabidopsis example of association mapping in structured samples. PLoS Genet. 3, e4. 